Original article

\title{
Quantitative study of Rickettsia massiliae in Rhipicephalus sanguineus organs
}

Natacha Milhano ${ }^{\mathrm{a}, *}$, Vsevolod Popov ${ }^{\mathrm{b}}$, Manuela Vilhenac ${ }^{\mathrm{c}}$, Donald H. Bouyer ${ }^{\mathrm{b}}$, Rita de Sousa ${ }^{\mathrm{a}}$, David H. Walker ${ }^{\mathrm{b}}$

"National Institute of Health Dr. Ricardo Jorge, Aguas de Moura, Portugal

bepartment of Pathology and Center for Biodefense and Emerging Infectious Diseases, The University of Texas Medical Branch, Calveston, TX, USA ¿ Department of Veterinary Medicine, Universidade de Evora, Evora, Portugal

\section{A R T I C L E I N F O}

Article history:

Received 11 january 2014

Received in revised form 8 May 2014

Accepted 12 May 2014

Available online 6 August 2014

\section{Keywords:}

Rhipicephalus sanguineus

Rickettsia massiliae

Ticks

Quantitative real-time PCR

Electron microscopy

\section{A B S T R A C T}

Rickettsia massiliae, belonging to the spotted fever group of Rickettsia, is a human pathogen causing a similar course of disease to that caused by $R$. conorii, the originally recognized etiologic agent of Mediterranean spotted fever. In view of this similarity, we performed an ultrastructural study of $R$. massiliae in organs of Rhipicephalus sanguineus ticks, in order to advance knowledge of the complex dynamics at the tick-pathogen interface in rickettsioses.

Adult $R$. massiliae-infected $R$ h. sanguineus ticks were fed on uninfected Hartley strain guinea pigs, and five females were collected daily throughout their feeding period up to day 6 , and analyzed by quantitative real-time PCR and electron microscopy. An increase in rickettsial content was observed in the salivary glands, particularly in the first two days of feeding, and a plateau was observed between days 3 and 6 . Rickettsial organisms were observed in all tick organs analyzed, in higher numbers in the fed state, and statistically significant differences were observed in measurements of the periplasmic layer of $R$. massiliae in salivary glands of fed and unfed $R h$. sanguineus ticks, with increased thickness in the former case.

This study provides insight into the interface between $R$. massiliae and $R h$. sanguineus ticks, highlighting the need for analysis of $R$ massiliae to fully ascertain its place as an important pathogenic agent of a spotted 